\title{
A Factorial Validation of Knowledge-Sharing Motivation Construct*
}

\author{
Qinxuan Gu, Yingting Gu \\ Antai School of Management, Shanghai Jiao Tong University, Shanghai, China. \\ Email: verasjtu66@yahoo.com,gu.yingting@yahoo.com.cn \\ Received November $14^{\text {th }}, 2010$; revised December $17^{\text {th }}, 2010$; accepted December $20^{\text {th }}, 2010$.
}

\begin{abstract}
While there is increasingly strategic importance in knowledge, it is facing new challenges to manage knowledge effectively. The paper studies the motivational construct model for knowledge sharing from the perspective of content theories and social motivation theories. The data collected by using the questionnaire survey from a variety of industries was analyzed on the basis of interviews and pretest. The results of exploratory factor analysis (EFA) and confirmatory factor analysis (CFA) showed the motivational construct model for knowledge sharing was comprised of existence motivation, relatedness motivation, growth motivation and norm motivation. The results extended the perspectives for knowledge sharing motivation and provided theoretical evidences for facilitating knowledge sharing behavior.
\end{abstract}

Keywords: Knowledge Sharing, Motivation, Norm, Content Theory, Factor Analysis

\section{Introduction}

With the continuous development of knowledge economy and economy globalization, competitive advantages and sustainable development of enterprises are increasingly dependent on knowledge and knowledge management. [1] As a key component of knowledge management, knowledge sharing is a force which facilitates knowledge exchange and transfer. It not only facilitates knowledge creation but also avoid the creation overlap. Therefore, knowledge sharing makes full use of spillover effect of knowledge, and then enhances organizational competitive advantages. In addition, knowledge is closely related to innovation [2].

People who are the carriers of knowledge share and create knowledge. On the other hand, knowledge sharing is not a spontaneous process. Those who master knowledge usually tend not to transfer and diffuse their knowledge. Considering protecting their own special status, the employees who have unique skills do not easily share their knowledge with others, especially when the knowledge come so uneasily and is so beneficial to him. Knowledge sharing has become a challenge for organizations in knowledge management (Grant, 1996) [3]. Evidences showed that contrary to the importance of know-

*This article is based on research sponsored by National Natural Science Foundation of China Grant 70771064. ledge sharing, ways to facilitate knowledge sharing at many organizations didn't achieve the expected results. Knowledge sharing, is becoming a difficult practice, affects the effective knowledge management in enterprises to a great extent [4-6]. Motivational factor is the key to knowledge sharing behavior $[8,9]$. Much literature contributed to individual knowledge sharing motivation from the perspective of content theories of motivation, however few of them focus on the social motivation of knowledge sharing [10]. Considering the complexity and sociability of knowledge sharing behavior, the purpose of this study is to explore the construct dimensions of sharing motivation systematically from the perspective of combining content theories and social motivation theories. To identify the knowledge-sharing construct, firstly, we conducted pre-research, then adopted two types of analyses-Exploratory Factor Analysis (EFA) and Confirmatory Factor Analysis (CFA) to establish four-component model of knowledge sharing. Moreover, theoretical contributions and practical implications of the findings have been discussed.

\section{Theoretical Background of Knowledge Sharing Motivation}

Motivation is the result of interaction of individuals and the situation (Robbins, 1992). It's the intention to make 
efforts for the organizational goal. But this kind of intention is subject to whether the efforts meet individuals' needs [11]. Scott and Walker claimed that motivation explains why people do something and why people behave, it's the source of driving continuous efforts [7].

For a long time, theorists used to study motivation theories from psychology, management. The typical examples are content theories of motivation. One of them is Maslow's Hierarchy of Needs Theory (physiological, safety, love/belonging, esteem, and self-actualization) [11], according to that, only when the lower needs are met, the higher needs can be met. However, this hierarchy theory wasn't fully support by subsequent empirical researches. Another theory is ERG theory, presented by Alderfer, which merged and developed Maslow's Hierarchy of Needs Theory. Existence is composed of physiological needs and safety; Relatedness refers to the desire of interaction and harmonious relationship with others, composed of belonging and esteem. Growth refers to the internal desire of development in career and work, composed of self-actualization. Alderfer proposed there is no hierarchy among these three kinds of needs. In other words, to meet the higher needs doesn't require that lower needs have been met [12]. Similar to ERG theory, another three-factor theory of needs was presented by McClelland. The theory includes need for affiliation, need for achievement and need for power, excluding economic, physiological and safety needs and dividing relationship needs and growth needs into need for affiliation, need for achievement and need for power [13]. Herzberg proposed Motivator-Hygiene Theory, which distinguishes hygiene factors that can eliminate dissatisfaction and motivators that can lead to satisfaction. Hygiene factors are composed of salary, status, interpersonal relationship, company policy, safety and security, etc. Motivators are composed of achievement, responsibility, recognition, advance and growth. Hygiene factors are the basic conditions to drive people to work. However, motivators are the factors to satisfy people's growth needs. These content theories of motivation can be applied to the research of motivation of knowledge sharing. In fact, these theories have been enriched and developed in the practices of manage knowledge workers' behavior [14].

Stott and Walker (1995) argued that according to Maslow's theory, knowledge worker do not tend to share knowledge for money or improving the relations with colleagues. Their motivations of knowledge sharing are to satisfy the three higher levels of needs: belonging, esteem and self-actualization [7]. In another word, they argued the motivations of knowledge sharing are not from the external or visible factors, but from the receptive or internal factors. Because belonging and esteem are reflected by relations and self-actualization is reflected by self-growth and development, the three kinds of motivations involve relationship and self-growth. Using Motivator-Hygiene Theory, Hendricks (1999) found that for knowledge workers at IT industry, motivations of knowledge sharing include achievement, responsibility, recognition and growth, instead of hygiene factors such as salary and status [15]. Hall (2001) found that invisible rewards such as enhancing reputation and satisfaction are the driving factors of knowledge sharing [8]. In addition, Hall (2001), Bartol \& Srivastava (2002) suggested that effective reward systems not only provide staff with visible reward, e.g. salary, stock, bonus, etc., but also encourages employees to share knowledge with other employees $[8,9]$. Prior research showed that visible economic rewards can also encourage knowledge sharing. Davenport \& Prusak (1998) pointed out knowledge sharing means a market where knowledge holders share their knowledge for rewards such as reciprocity, reputation, altruism [16]. Reciprocity refers to the probability by which the seller of knowledge expect the buyer to give him a hand when necessary. The higher the probability, the more time and money the seller will spend on knowledge sharing. Although reputation is invisible, it brings visible benefits. Having a reputation of knowledge sharing is helpful to reciprocal behavior. And the reputation as a knowledge seller makes a person a more efficient knowledge buyer or enhances the possibility of promotion. Altruists have no expectations on repayment, but they hope that their knowledge can be diffused. When the knowledge holders don't believe that the knowledge sharing get the expected results, the sharing will be hindered. Therefore, the motivations of reciprocity, reputation and altruism are related to the interpersonal relationship [18].

The existing research stressed on content theories of motivation, that is to say they focused on rewards and incentives, ranging from visible rewards to invisible rewards, from external return to internal feeling, involving economic return (the direct or indirect), relationship and achievement or growth, etc.

However, some researchers argued that content theories of motivation explain how the knowledge exchange is encouraged, but the theories fail adequately to explain the knowledge sharing [10]. Knowledge sharing includes knowledge exchange and transfer, meaning receiving others' knowledge while transferring their knowledge. Moorman \& Miner (1998) suggested knowledge sharing is collective belief and code of conduct about learning among individuals or between departments in organizations [17]. Knowledge sharing, fundamentally, is a social process $[9,10]$. Knowledge lies in different levels of organization, including individual level, group level and 
organizational level. Among these levels, knowledge sharing among individuals is the key to shaping organizational knowledge. The social factors that facilitate knowledge provider and receiver are necessary to strengthen sharing motivation. Social motivation theory originated from the research in peer influences [10]. Norms that come from interpersonal interaction are group agreements and social motivation mechanisms. The norms influence individual motivations indirectly by acknowledge the existing influencing mechanism of motivation $[10,20]$. Norms represent the consistency of cognition and judgment people have towards behavior in a social system [20]. Feldman suggested norms are used to restrain important behaviors in organizations. When people feel some special behavior can bring them more outcomes, they will put forward and define the norms [20]. Therefore, norms make people's behaviors meet the group's or organization's expectations. Studies showed that norms of knowledge sharing are playing an important role in encouraging knowledge providers to share their knowledge [20,23].

Thus, we found that among the prior research, more studies on the knowledge sharing motivation from the traditional content theories, whereas fewer studies from social motivation, less study from the combination of two different perspectives. Knowledge sharing among individuals is a complex process, is driving by different motivations. This present study combines the content theories and social motivation theories to discuss the dimensions of knowledge sharing motivation.

\section{Development of Knowledge-Sharing Motivation Construct}

\subsection{Pre-Research}

Pre-research explored the construct model of knowledge sharing motivation with the original questionnaire by following three steps.

Step 1: semi-structured interview. The process was, 1) by analyzing existing literatures, determined the major interview questions on aspects of direct economic reward and indirect economic reward, relationship, growth and norm, and design the open questions; 2) discussed with the interviewees about the types of behavior motivations, the definition of knowledge sharing, motivations of knowledge sharing behavior and the main features; 3 ) asked the interviewees in details according to the designed questions, and ask the interviewees to illustrate and give more supplementary questions. Eight persons were interviewed, including three HR managers, two R\&D professionals, one technician and two project managers from six enterprises, three foreign-owned enterprises, two state-owned enterprises and one private en- terprise. The interview time was ranged from 45 minutes to 60 minutes for per person.

Step 2: code of interview transcripts and design of questionnaire. The process was, 1) analyzing the interview transcripts and extracting the content that influence the knowledge sharing behavior; 2) classifying the content extracted into the four aspects of semi--structured interview; 3) conducting statistics \& analysis of the frequency of all kinds of the content, discussing the overlapped, 15 items on knowledge sharing motivations concluded 4) three professors and two senior managers were invited to appraise and amend the reasonableness and the expression of the 15 items, and 1 ambiguous item deleted and 14 items kept which consist of the initiative questionnaire.

Step 3: pre-test and determination of the questionnaire. pretest using the samples from MBA students at one university in Shanghai. 53 questionnaires collected were valid. Conducting exploratory factor analysis and item analysis, one item cross loading was deleted, 13 items were retained for next survey.

\subsection{Data Collection and Sample Description}

Using the pre-tested questionnaire to conduct large-scale survey for exploring and test the construct of knowledge sharing. The variables included contextual variables, independent variable and dependent variables. Contextual variables referred to personal information such as gender, age, education. Independent variable was knowledge sharing motivation. Dependent variables were knowledge sharing behavior. Independent variable and dependent variables used 5-point Likert scales. The respondents were the knowledge employees graduated from college or above, from over 200 enterprises in Shanghai, Jiangsu, Anhui, Zhejiang, Fujian, Guangdong, and Shenzhen. Of the 600 questionnaires distributed, 451 were returned, and 419 were valid, the valid rate was $69.8 \%$. Among the 419 valid questionnaires, $62.8 \%$ male, $35.7 \%$ female, $1.5 \% \mathrm{NA} ; 3.0 \%$ between the age of $21-25$, $27.6 \%$ between $26-30,32.5 \%$ between $31-35,29.1 \%$ between $36-45,7.9 \%$ over $46 ; 11.3 \%$ graduated from college, $42.1 \%$ from university, $33.7 \%$ with master degree, $12.3 \%$ with $\mathrm{PhD}$ degree, $0.5 \%$ NA.

Due to the collection of all measures from the same source, there might be common method variance influencing the research conclusions. Thus, we used the Harman one-factor test to examine the potential problem of common method variance. Significant common method variance would result if one general factor accounts for the majority of variance in the variables [21]. A principle factor analysis on the measurement items of this study yielded six factors with eigenvalues greater than one that accounts for $68.126 \%$ of the total variance, and the first 
factor accounted for $17.497 \%$ for the variance. Since a single factor does not emerge and one general factor does not account for most of the variance, common method bias is unlikely to be a serious problem in the data [21].

\subsection{The Construct of Knowledge Sharing Motivation}

To explore and construct knowledge sharing motivations, we used SPSS15.0 to analyze the data and principal components factor analysis with varimax rotation. This samples collected had a larger scale $(\mathrm{N}=419)$. in terms of 13 items from previous research according to 1:10 ratio. We divided the samples into two groups, one used for exploratory factor analysis $(\mathrm{N}=210)$, the other used for confirmatory factor analysis $(\mathrm{N}=209)$, in order to get results with cross validation.

The exploratory factor analysis yielded four factors, as shown in Table 1. The factors with eigenvalues greater than one that accounts for $69.254 \%$ of the total variance and each factor accounted from $14.084 \%$ to 19.409 for the variance. The load coefficient of each factor was greater than 0.6. According to the content theories and social norm theories, we explained and defined the four factors as follows:

The first factor contains three items: salary, bonus and job security. It reflects knowledge sharing player's needs for physiological and safety corresponds to the existence needs of Alderfer's ERG theory [12]. Thus, we defined it as existence motivation.

The second factor contains four items: group membership, recognition of expertise, professionalism and reputation \& esteem. It reflects that knowledge sharing player's expectations to maintain his or her membership and positive interpersonal or social relationship. Thus, we defined it as relationship motivation.

The third factor contains three items: growth and development, achievement and good self-feeling. It reflects knowledge sharing player's needs for feeling and growth. Thus, we defined it as growth motivation.

The fourth factor contains three items: responsibility to knowledge sharing as an organizational member; knowledge as a public good shared by people; knowledge belongs to organizations rather than individuals. It reflects that knowledge sharing player's desires to engage agreements of the interacted group or organization. Thus, we defined it as norm motivation.

By exploratory factor analysis, we found that the motivations to share knowledge are composed of four factors consisting of existence, relationship, growth and norm.

Table 1. Results of exploratory factor analysis $(\mathrm{N}=\mathbf{2 1 0})$.

\begin{tabular}{|c|c|c|c|c|}
\hline \multirow{2}{*}{ Item } & \multicolumn{4}{|c|}{ Factor loading } \\
\hline & 1 & 2 & 3 & 4 \\
\hline 1. Salary/ bonus to be increased & 0.835 & 0.096 & -0.077 & -0.046 \\
\hline 2. Reword to be received & 0.764 & 0.27 & 0.208 & -0.002 \\
\hline 3.Job security to be enhanced & 0.615 & 0.237 & 0.035 & 0.344 \\
\hline 4.Group Membership To Be Held & 0.014 & 0.65 & 0.061 & 0.357 \\
\hline 5. Expertise to be recognized & 0.143 & 0.783 & 0.187 & 0.106 \\
\hline 6. Status as expert to be got & 0.26 & 0.799 & 0.124 & 0.022 \\
\hline 7. Reputation and esteem & 0.252 & 0.766 & 0.219 & 0.013 \\
\hline 8.Learning more knowledge and growth \& development & 0.105 & 0.141 & 0.721 & 0.169 \\
\hline 9. Achievement & 0.034 & 0.178 & 0.856 & 0.176 \\
\hline 10. Good self-feeling from knowledge sharing & -0.014 & 0.153 & 0.819 & 0.17 \\
\hline 11. Responsibility to share & 0.049 & 0.153 & 0.366 & 0.721 \\
\hline 12. Knowledge as a public goods, shared by people & 0.065 & 0.067 & 0.269 & 0.837 \\
\hline 13. Knowledge belonged to organizations rather than individuals & 0.039 & 0.072 & 0.045 & 0.892 \\
\hline Eigenvalues & 1.831 & 2.523 & 2.285 & 2.364 \\
\hline The rate of variance explained $\%$ & 14.084 & 19.409 & 17.575 & 18.186 \\
\hline
\end{tabular}




\subsection{Confirmation of Knowledge-Sharing Motivation Construct}

On the basis of exploratory factor analysis, we used AMOS 7.0 to conduct confirmatory factor analysis for the construct of knowledge sharing motivation. To confirm whether the four-factor model is the optimization model, according to the literature review above, we proposed two candidate models including a two-component model and a three-component model. Then, we compared the three models to decide which one is the optimization model. A two-component model was proposed according to content theories of motivation and social motivation theories. Existence, relationship and growth, each of them is part of content theories, are integrated into one component, norm is the other component which is involved in social influence mechanisms. A three-component model is to put the content motivations into two categories: existence and relationship are involved in external motivations and integrated into one component; whereas growth is involved in internal motivation and belongs to another component.

We used the other half of data to conduct confirmatory factor analysis by AMOS 7.0, and got fit indices of the three models, as shown in Table 2. Expectation value of $X^{2} / \mathrm{df}$ is 1 , the more close to 1 , the fitter the model is. If $X^{2} / \mathrm{df}<3$, the whole model is good [22]. If RMSEA $<$ 0.05 , the fitness is good; and if RMSEA $<0.08$, the fitness is acceptable [23]. There are other fit indices, such as NFI, NNFI, GFI, CFI, IFI, the values between 0 and 1 , the bigger the value, the good the fitness. The usual requirement is that these indices are bigger than 0.90 . Compared with these fitness requirements, the 4-component model was the optimization model. The fit indices showed the construct model fits the observed data very well. Furthermore, we tested the reliability of four components, and found the Cronbach $\alpha$ are 0.661, 0.804, 0.794 and 0.836 , respectively. Except the reliability of existence was a little low, the other components' Cronbach $\alpha$ were bigger than 0.70 . The whole Cronbach $\alpha$ is 0.831 , indicating that the reliability of the four components was good.

Finally, we used second-order CFA to test convergent validity of dimensions of knowledge sharing motivation, taking knowledge sharing motivation as second-order factor, four dimensions as first-order factor. The conclusion showed that the fitness is good $\left(\chi^{2}=1.766, \mathrm{df}=1\right.$, $\chi^{2} / \mathrm{df}=1.766$, RMSEA $=0.044$, GFI $=0.998, \mathrm{CFI}=$ $0.997, \mathrm{IFI}=0.997, \mathrm{NFI}=0.993, \mathrm{NNFI}=0.982)$. And the factor loadings of second-order factors (relationship, growth and norm) were over 0.50 with 0.001 in significance. The factor loading of existence was a little low, 0.21 , with 0.001 in significance. The model showed that there is a common latent variable behind the four dimensions, which is knowledge sharing motivation variable.

\section{Discussion and Implications}

\subsection{Discussion}

This paper studied conceptualization of knowledge sharing motivation by using samples of knowledge workers from the perspectives of combining content theories of motivation and social motivation theories. This present study suggested a four-component model of knowledge sharing motivation which consists of existence, relationship, growth and norm. This result showed that knowledge sharing is a complex social process. Knowledge workers have mastered knowledge, skills and expertise, thus, they become important knowledge sharing players. As most people, they may care about the economic reward, job security or stability. However, to some extent, knowledge workers are different from most people, they pay more attention to the internal gratification and growth from knowledge sharing, focusing on the realization of self-value and desire for recognitions from the group, organization and others. In addition, knowledge workers are typically members of a society, an organization or a group, so, their knowledge sharing behavior is under some social situation. If an organization or group has shaped knowledge sharing norms, the norms will be a driving force to facilitate knowledge sharing among individuals in organizations or groups.

\subsection{Theoretical Contributions and Practical Implications}

\subsubsection{Theoretical Contributions}

First, this present study enlarged the view of knowledge sharing motivation through combination of content theories of motivations and social motivation theories. Traditional content theories of motivations tend to encourage

Table 2. Resulis of confirmatory factor analysis $(\mathrm{N}=209)$.

\begin{tabular}{cccccccccccc}
\hline Model & $\chi^{2}$ & $\boldsymbol{d} \boldsymbol{f}$ & $\chi^{2} / \boldsymbol{d} \boldsymbol{f}$ & RMSEA & GFI & CFI & IFI & NFI & NNFI \\
\hline 2-component Model & 662.079 & 64 & 10.345 & 0.152 & 0.778 & 0.739 & 0.741 & 0.721 & 0.682 \\
3-component Model & 332.454 & 62 & 5.362 & 0.104 & 0.89 & 0.882 & 0.883 & 0.86 & 0.851 \\
4-component Model & 98.43 & 46 & 2.139 & 0.053 & 0.965 & 0.977 & 0.977 & 0.958 & 0.961 \\
\hline
\end{tabular}


knowledge exchange behavior, but they fail adequately to explain knowledge sharing behavior, that is to say while receiving others' knowledge, people transfer their knowledge to others. Social motivation theories make up the deficiency of content theories in knowledge sharing. Knowledge sharing is complex process in which individuals behave under specific social situations, with interpersonal relationship and interaction. Social motivation theory argues that social influence mechanisms such as norms can influence behaviors by serving to intensify or strengthen to motivational tendencies of structural features such as incentives [10]. Specifically, norms that support knowledge sharing may accentuate the influence. In other words, the norms which come from interpersonal interaction significantly influence or strengthen knowledge sharing behavior. The four-component construct of knowledge sharing motivation concluded in basis of the combination of content theories and social motivation theories enriched the theoretical views about individual motivation to share knowledge. Our findings suggested knowledge sharing is a complex process involving in individual behaviors under the particular social context.

\subsubsection{Practical Implications}

The study provided a few practical implications. First, when facilitating employees to share knowledge, managers should pay attention to the individual's motivation factors, especially to relationship and growth, recognition, expert status and esteem, and encourage employees to learn from each other in an organization, to respect each other; to grow and develop, to realize their values. Managers also should highlight social motivation factors by setting up knowledge sharing norms in an organization and having individuals aware of the organizational norms. The cognitions of knowledge as a public good and belongings to organizations should be strengthen, and make knowledge workers recognize responsibility to share knowledge with others.

\subsection{Limitations}

There were several limitations in this study that should be taken into account in the further study. First, the study of social motivation was limited to norm motivation, didn't involve other types of social motivations, like interpersonal trust motivation. Further research should be expanded on shared social motivations. Second, the data was collected from the coastal areas in China, which didn't cover the central and western regions in China. The geographical limitation may affect the ecological validity

\section{REFERENCES}

[1] L. Argote and P. Ingram, "Knowledge Transfer: A Basis of Competitive Advantage in Firms," Organizatianal Behavior and Human Decision Processes, Vol. 82, No. 5, 2000, pp. 150-169.

doi:10.1006/obhd.2000.2893

[2] I. Nonaka and N. Konno, "The Concept of 'Ba': Building a Foundation for Knowledge Creation," California Management Review, Vol. 40, No. 1, 1998, pp. 1-15.

[3] R. M. Grant, "Toward a Knowledge-Based Theory of the Firm," Strategy Management Journal, Vol. 17, Winter Special Issue, 1996, pp. 109-122.

[4] G. Szulanski, "Exploring Internal Stickiness: Impediments to the Transfer of Best Practice within the Firm," Strategic Management Journal, Vol. 17, Winter Special Issue, 1996, pp. 27-43.

[5] M. Alavi and D. E. Leidner, "Review: Knowledge Management and Knowledge Management Systems: Conceptual Foundations and Research Issues," MIS Quarterly, Vol. 25, No. 1, 2001, pp. 107-136. doi: $10.2307 / 3250961$

[6] A. Cabrera and E. F. Cabrera, "Knowledge-Sharing Dilemmas," Organization Studies, Vol. 23, No. 5, 2002, pp. $687-710$. doi:10.1177/0170840602235001

[7] K. Stott and A. Walker, "Teams Teambuilding: The Manager's Complete Guide to Teams in Organizations," Prentice Hall, New York, 1995.

[8] H. Hall, "Input-Friendliness: Motivating Knowledge Sharing Across Intranets," Journal of Information Science, Vol. 27, No. 3, 2001, pp. 139-146. doi: $10.1177 / 016555150102700303$

[9] K. M. Bartol and A. Srivastava, "Encouraging Knowledge Sharing: The Role of Organizational Reward Systems," Journal of Leadership \& Organizational Studies, Vol. 9, No. 1, 2002, pp. 64-77. doi: $10.1177 / 107179190200900105$

[10] N. R. Quigley, P. Tesluk, E. Locke and K. Bartol, “A Multilevel Investigation of Motivational Mechanisms Underlying Knowledge Sharing and Performance," Organizational Science, Vol. 18, No. 1, 2007, pp. 71-88.

[11] A. H. Maslow, “Towards a Psychology of Being," Van Nostrand, New York, 1968.

[12] C. P. Alderfer, "Existence, Relatedness and Growth," Free Press, New York, 1972.

[13] D. C. McClelland, "Human Motivation," Cambridge University Press, Cambridge, 1987.

[14] G. Herzberg, "Molecular Spectra and Molecular Structure," Van Nostrand Reinbold, New York, 1966.

[15] P. Hendricks, "Why Share Knowledge? The Influence of ICT on Motivation for Knowledge Sharing," Knowledge and Process Management, Vol. 6, No. 2, 1999, pp. 91-100. doi:10.1002/(SICI)1099-1441(199906)6:2<91::AID-KPM $\underline{54>3.0 . \mathrm{CO} ; 2-\mathrm{M}}$

[16] T. H. Davenport and L. Prusak, "Working Knowledge: How Organizations Manage What They Know," Harvard Business School Press, Boston, 1998.

[17] C. Moorman and A. S. Miner, "Organizational Improvi- 
sation and Organizational Memory," Annual Review, Vol. 23, No. 4, 1998, pp. 698-723.

[18] R. G. Geen, "Social Motivation," Pediatrics, Vol. 42, No. 1, 1991, pp. 377-399.

[19] J. L. Coleman, Jr., "Comparison of Depositional Elements of an Ancient and a 'Modern' Submarine Fan Complex: Early Pennsylvanian Jackfork and Late Pleistocene Mississippi Fans (abs.)," AAPG Bulletin, Vol. 74, 1990, p. 631.

[20] D. Feldman, "The Development and Enforcement of Group Norms," Academy of Management Review, Vol. 9, No. 1, 1984, pp. 47-53. doi: $10.2307 / 258231$

[21] P. Podsakoff and D. Organ, "Self-Reports in Organizational Research: Problems and Prospects," Journal of Management, Vol. 12, No. 4, 1986, pp. 531-544. doi: $10.1177 / 014920638601200408$

[22] K. G. Joreskog and D. Sorborm, "LISREL 8: Structural Equation Modeling with the SIMPLIS Command Language," Scientific Software, Chicago, 1993.

[23] R. P. McDonald and M. R. Ho, "Principles and Practice in Reporting Structural Equation Analysis," Psychological Methods, Vol. 7, No. 1, 2002, pp. 64-82. doi:10.1037/1082-989X.7.1.64 